\title{
LA GUERRA EN ALGUNOS POETAS LÍRICOS DEL SIGLO XVII
}

\author{
ANTONIO CARREIRA
}

Heráclito lo había dicho en uno de sus aforismos: «Guerra es el padre de todos, rey de todos; a unos ha acreditado como dioses, a otros como hombres; a unos ha hecho esclavos, a otros libres». ${ }^{1}$ Los exegetas pueden comentar que Heráclito es muy oscuro, y que en ese contexto la palabra guerra no equivale necesariamente a lo que hoy: pero el término original, pólemos, sí significa 'guerra', aunque en traducción española cambie de género. Cuando Heráclito quiere decir discordia usa la palabra eris. Por supuesto, este filósofo no es ningún padre de la Iglesia, aunque sí una autoridad que influye indirectamente en todo el pensamiento antiguo; y tampoco los poetas son filósofos. Su consideración de la guerra es doble: en primer lugar, la épica la tiene casi por tema único, a partir de modelos como Lucano y Virgilio, y a través de este, de Homero;

${ }^{1}$ Recibido: 17/XI/2009 Aceptado: 14/I/2010

Los filósofos presocráticos, trad. de Conrado Eggers Lan y Victoria E. Juliá (Madrid: Gredos, 1978), I, p. 347 (fr. B 53). 
en segundo, las guerras fueron siempre el fundamento de los imperios, y la lírica no podía soslayarla. Leyendo a unos y otros se obtiene la impresión de que la guerra para nuestros antepasados no es algo lamentable y diabólico, sino la ocasión ideal donde los hombres muestran lo mejor y lo peor de sí mismos, algo, pues, implícito en la naturaleza humana y que en cierto modo sirve para exaltarla. La actitud pacifista a ultranza, que desde la moda hippy asoma como algo espontáneo, a ellos les hubiera parecido enfermiza e impropia de un talante viril. Sin guerrear no era posible conquistar tierras, ni tampoco mantenerlas y defenderse de enemigos pertinaces en sus ataques, como lo fueron en la época turcos, berberiscos, franceses, ingleses y holandeses. Pero en aquella España hubo también rebeliones internas: la de los Comuneros y la de los Moriscos en el siglo XVI, las de Cataluña y Portugal en el XVII, sin hablar de los conflictos que tuvieron lugar en suelo italiano, parte del cual se disputaba con Francia. La guerra era, así, el pan nuestro de cada día: las ciudades estaban amuralladas, las costas vigiladas, las flotas protegidas y escoltadas, las levas eran frecuentes, no se podía bajar la guardia. Es obvio también que, en el caso español, la guerra casi siempre tuvo implicaciones religiosas o se quiso justificar con ellas. Al rey español se le llamaba Su Católica Majestad, y por tanto Dios estaba de su parte cuando luchaba contra gentes de otro credo. No era exactamente el yihad, pero tampoco estaba lejos de serlo, ya que el país mismo derivaba su existencia de algo similar: la guerra de reconquista contra el infiel.

Esto no debe olvidarse al considerar la visión de la guerra en la lírica. Cierto es que en ella constituye un tema muy secundario; de hecho son bastantes los poetas que ni lo rozan: los Argensola, Medrano, Liñán de Riaza, Arguijo, Rioja, Juan de Salinas, el conde de Salinas, Luis Martín de la Plaza, Antonio de Mendoza, Soto de Rojas, entre los del XVII, si recuerdan alguna guerra es la de Troya, o, como más próxima, la civil entre César y Pompeyo. Las contiendas en que España se ve envuelta apenas inspiran a nuestros líricos, pero algunos de vez en cuando se sienten obligados a celebrar victorias, exaltar próceres o desear buen suceso a empresas bélicas. Con todo, puede afirmarse que son más los poemas líricos dedicados a hazañas cinegéticas o circenses (como la de Felipe IV cuando mató un toro disparándole desde un balcón) que los inspirados por hechos militares. No en vano hombre de letras en los siglos de oro era casi sinónimo de clérigo, o, sin casi, de cortesano en sentido lato, es decir, alguien a quien la guerra le quedaba muy lejos y de la que tenía noticias esporádicas, según llegaban los correos o las gacetas. ${ }^{2}$

\footnotetext{
2 Conocemos solo dos libros que se han ocupado de algo similar: Poesía heroica del imperio, antología y prólogos de Luis Rosales y Luis Felipe Vivanco (Barcelona: Jerarquía, 1940, 2 vols. de 580 y 743 pp.), cuyo título entiende el término heroico en su más amplio sentido, pues incluye epitafios, encomios, poesía moral, romances y fragmentos épicos. Naturalmente, entre tanta selección no faltan los poemas dedicados a la guerra y a la milicia. Por desgracia, se alteran o inventan los epígrafes, no se anotan los
} 
En efecto, el tópico de atender por igual a la pluma y a la espada afecta a pocos autores. Garcilaso apenas hizo más referencias a la guerra que el conocido soneto XVI «No las francesas armas odiosas», que sirve de epitafio a su hermano. Un epitafio curioso, porque viene a decir que a don Fernando de Guzmán, tras tanto pelear, se lo llevó una «infición de aire», o un aire corrupto, según entonces se llamaba; hasta ese punto puede ser ingrato el destino con un militar aguerrido. El siguiente poeta soldado, al menos parte su vida, Hernando de Acuña (1518-1580), escribió el célebre soneto «Ya se acerca, señor, o ya es llegada», dedicado al Felipe II, y es la única ocasión en que Acuña recuerda la milicia. ${ }^{3}$ Viene después el capitán Aldana, quien, como Garcilaso, murió con la espada en la mano. Su obra toca más teclas, pero solo deja vislumbrar la guerra en dos poemas. El primero, un excelente soneto, merece que lo recordemos, porque constituye la mejor descripción de ella vista desde dentro:

Otro aquí no se ve que, frente a frente, animoso escuadrón moverse guerra, sangriento humor teñir la verde tierra $\mathrm{y}$ tras honroso fin correr la gente;

este es el dulce son que acá se siente: «iEspaña, Santïago, cierra, cierra!», y por suave olor, que el aire atierra, humo de azufre dar con llama ardiente.

El gusto envuelto va tras corrompida agua, y el tacto sólo apalpa y halla duro trofeo de acero ensangrentado, hueso en astilla, en él carne molida, despedazado arnés, rasgada malla. ¡Oh solo de hombres dino y noble estado! ${ }^{4}$

La ambigüedad del último verso es tan formidable que hasta hoy no hay acuerdo en saber si el epifonema es serio o irónico. Menos conocido resulta un largo fragmento de la «Carta a un amigo, al cual le llama Galanio», vv. 150-246, en el que se pinta un rebato nocturno, con hábil uso del encabalgamiento:

Aquél su cuerda enciende, éste su mecha sopla, de balas éste boca y bolsa hinche; quien la trabada y vieja malla cubre, quien la manopla y la celada

poemas ni se indica su fuente ni se da más bibliografía que la citada en los prólogos. El otro es Armas y letras en el siglo de oro español (Antología poética), de Víctor García de la Concha, Abraham Madroñal y Mercedes Sánchez (Madrid: Ministerio de Defensa, 1998, 245 pp.). También incluye fragmentos épicos y alguno dramático, antepone un breve prefacio a cada autor e indica la procedencia de los textos (pp. 19-22).

3 Varias poesías, ed. de Luis F. Díaz Larios (Madrid: Cátedra, 1982), p. 328. Cf. Christopher Maurer, «Un monarca, un imperio y una espada: Juan Latino y el soneto de Hernando de Acuña sobre Lepanto», Hispanic Review, 61 (1993), pp. 35-51.

4 Aldana, Poesías castellanas completas, ed. de José Lara Garrido (Madrid: Cátedra, 1985), p. 344. 
toma, quien el arnés trabado encima
carga, quien del almete y la coraza
traba, quien la jineta o la alabarda
coge, quien espaldar y peto junto
ata, quien una y otra pieza luego
trueca, quien el quijote sobre el muslo
pega, quien la escarnosa coracina
ase, quien grebas, bufa y contrabufa
pone, quien tachonadas taherías
ciñe y se enlaza con presteza el yelmo.

Pasaje al que sigue el nerviosismo del caballo, ansioso por acometer, para luego quedar todo en una falsa alarma. No hay duda de que Aldana sentía la belleza salvaje de la guerra, que era su profesión y le costó la vida.

Muy poco es lo que se sabe del repentista Juan Bautista de Vivar, amigo de Cervantes y tal vez soldado, muerto hacia 1591, a quien se atribuyen dos poemas breves en octavas en defensa de la vida militar: «A saber emplear la amada vida», impreso en $1594,{ }^{6}$ y «A sido siempre el béllico exercitio», conservado en un manuscrito italiano. ${ }^{7}$ Vivar se toma muy en serio la profesión, que para él «es una fragua donde el mundo apura / valientes y cobardes coraçones, / porque la guerra a veces disfigura / los que en la paz se pintan por leones», como dice en el primer poema; en el segundo afirma que en ella se guarda la amistad, la honra y la justicia, en tal medida que las armas son camino seguro del cielo. Pronto veremos que sus colegas distaban de creer lo mismo.

El cordobés Luis Carrillo y Sotomayor (1585-1611) fue cuatralbo de galeras e ingenio malogrado, puesto que murió con 24 años. En su breve obra poética las referencias a la milicia son muy escasas: un soneto («Usurpa ufano ya el tirano viento») en el que lamenta la ausencia de la amada mientras él se aleja en la galera, y el romance «A la caza de unas galeotas turquescas», que narra una empresa bélica frustrada, al revés que el romance de Pedro Espinosa titulado «Encomio de la victoria del duque sobre una goleta turca», única incursión por su parte en la materia. ${ }^{8}$

El capitán valenciano Andrés Rey de Artieda (1549-1613), contemporáneo de Cervantes, en sus Discursos, epístolas y epigramas de Artemidoro (1605) hace referencias, y

\footnotetext{
${ }^{5}$ Ibid., p. 365.

6 Primer quaderno de varios romances, Impresso en Valencia, junto al molino de la Rouella, Año 1594 (R. Foulché-Delbosc, «Les Romancerillos de la Bibliothèque Ambrosienne», Revue Hispanique, XLV, 1919, pp. 591-592).

7 Cf. Abraham Madroñal, «Entre alegre esperanza y triste olvido (Versos inéditos de Juan Bautista de Vivar en la Biblioteca Riccardiana de Florencia)», Anales Cervantinos, XXXVI (2004), pp. 128-129.

8 Espinosa, Poesías completas, ed. de Francisco López Estrada (Madrid: Espasa-Calpe, 1975), p. 190. Se reproduce, con precisiones que amplían el relato, en Obras en prosa, ed. de López Estrada (Málaga: Diputación, 1991), pp. 249-253. El hecho, al parecer, tuvo lugar en 1599, cuando el duque era conde de Niebla.
} 
nada entusiastas, a la vida militar, en la que vio perecer a su primogénito. Por ejemplo, en los sonetos «A una comida de soldados, sobre la elección del cabo de esquadra», «A un soldado camarada del capitán: Antonio Vázquez», «A Cascajales, retirado de la soldadesca», $\mathrm{y}$ «Al estado presente de la soldadesca» (este dialogado o compuesto al alimón entre Artieda y Vázquez), que ponen en solfa la profesión de las armas. ${ }^{9}$ Más célebre es el titulado «A los discursos vanos», cuyo contenido recrea el cuento de la lechera con un soldado de protagonista:

Como, a su parecer, la bruxa buela, y untada se encarama y precipita, así un soldado, dentro una garita, esto pensava, haziendo centinela:

«No me falta manopla ni escarcela, mañana soy alférez, ¿quién lo quita?, y sirviendo a Felipe y Margarita, embraço y tengo paje de rodela.

Vengo a ser general, corro la costa, a Chipre gano, príncipe me nombro, y por rey me corono en Famagosta.

Reconozco al de España, al turco asombro...» Con esto se acabó de hazer la posta y hallose en cuerpo, con la pica al hombro. ${ }^{10}$

Otro igual de incisivo se debe al mencionado Sargento Mayor Antonio Vázquez, camarada de Artieda conocido por haber parafraseado el soneto de Góngora «Mientras por competir con tu cabello» para convertirlo en vituperio de la vejez. El que ahora nos interesa se titula «Del mismo a las pretenciones militares» y dice así:

Cruzar caminos, emfadar naciones, mudar de camas, vinos diferentes, ayres fríos, templados y calientes, costumbres varias, varias opiniones;

desquixajar serpientes y leones (que es domar unas gentes y otras gentes) rompiendo siempre por inconvenientes y siempre esclavo de las sinrazones, os darán diez escudos de ventaja pagados por la mano de un verdugo enemigo mortal del trato humano,

y a largos años, cuando al cielo plugo que veáys parte dellos en la mano, será para comprar una mortaja. ${ }^{11}$

\footnotetext{
9 Andrés Rey de Artieda, Discursos, epístolas y epigramas de Artemidoro (Zaragoza: Angelo Tavanno, 1605), ed. de Antonio Vilanova (Barcelona: Selecciones Bibliófilas, 1955), pp. 210, 218, 222 y 226.

$10 \quad$ Ibid., p. 212.

11 Ibid., p. 221. Otro soneto del mismo no poco irreverente con la milicia comienza «Del capitán es camarada Urbina» (p. 218).
} 
Difícilmente se podrá encontrar mejor trazado el reverso de la medalla heroica. La inclusión del soneto en el libro de Artieda parece indicar por su parte algo más que una aprobación estética.

El poeta lírico y dramático Cristóbal de Virués (1550-1614), asimismo capitán, valenciano y coetáneo de Cervantes, se duele de que la profesión militar esté mal vista por la plebe en un soneto enérgico pero algo falto de ironía.

$¡ O$ miserable suerte de soldados, de todo el universo aborrecidos, por desgracia i miseria dél tenidos, con mil impropios nombres denostados!

Quién nos llama cavallos desbocados, quién, lobos carniceros i atrevidos, quién, toros acossados i afligidos, quién, leones sangrientos i aquexados.

¿A quién llamáis assí, gente plebea? ¿A quien da reinos, cetros i coronas, con su sangre ganándolo i sus vidas?

¿A quién assí llamáis?, ¿a quien se emplea en guardaros haziendas i personas de vuestras ambiciones perseguidas? ${ }^{12}$

También ingenua, y prosaica, es la Égloga de la Batalla Naval de Lepanto, en la que Virués participó, así que al menos sirve como relato de primera mano. ${ }^{13}$ Mayor atractivo tienen, para nuestros fines, el soneto «Una desierta, peligrosa playa», sobre Barleta (f. 262), y el dedicado al combate de Navarino, que merece ser transcrito en su totalidad:

Escaramuças, sitio, batería, máquinas i otras grandes diligencias a avido en Navarín, con diferencias que en varios pechos vario tiempo cría.

A punto estar de verse otro gran día como el de antaño, i en sus apariencias mayor, si uviera las correspondencias que el enemigo bravo prometía.

No faltó por el de Austria valeroso ni por alguno del cristiano vando.

El Turco retirosse temeroso,

en cuya fe el Baçán valiente osando, una galera acometió furioso i, rendida, la traxo remolcando. ${ }^{14}$

12 Obras trágicas y líricas del capitán Cristóbal de Virués (Madrid: Alonso Martín, 1609), f. 227.

13 Ibid., ff. 233-249v.

14 Ibid., f. 249v. 
Selim II hizo almirante al renegado calabrés El Uchalí, bey de Argel. Este, tras la batalla de Lepanto (1571), aludida en el segundo cuarteto, pudo salvar parte de la escuadra turca refugiándose en Modón (actual Methoni), al sur de Morea, puerto que fortificó. Al año siguiente en Navarino (la antigua Pilos), donde también se halló Cervantes, no hubo combate naval propiamente dicho, aunque la galera «La Loba», de don Álvaro de Bazán, tomó al abordaje «La Presa», mandada por un joven de 22 años nieto de Barbarroja, que fue degollado por su espalder. El soneto de Virués es enigmático: elogia sin reservas la escuadra cristiana y sus jefes, pero tras doce versos rimbombantes ver a todo un marqués de Santa Cruz remolcando una sola galera como trofeo deja en el lector una impresión penosa, de la que participaban muchos españoles: la de haberse perdido una buena ocasión de terminar la tarea comenzada en Lepanto. ${ }^{15}$ Si quedaran dudas acerca de la interpretación, las disipa el final del soneto autobiográfico «Flaco i cansado del camino largo»: «Remedio a Vngría i Grecia en sus afanes / i triunfos esperávamos navales. / ¡Ai esperanças de los hombres vanas!» (f. 274).

No es el único caso en que Virués muestra su decepción por los asuntos militares, en los que había demasiados intereses entremezclados. El siguiente soneto apela a un motivo clásico (Horacio, Ars, 139) para expresarlo:

Montes Marte, de horror, montes de guerra

en Levante levanta en alto estruendo, preñados dél, a España prometiendo, tras Grecia i Tracia, la sagrada tierra.

El gran punto del parto que en sí encierra tan alto bien el mundo está atendiendo, la armada de Filipe i Malta viendo, que los puertos de Grecia i Tracia aferra.

I viéndola de gentes soberanas llena, i de capitanes valerosos, i de mil invencibles Rodomontes,

¡ai esperanças de los ombres vanas!, este parto esperávamos gozosos i fue un ratón el parto de estos montes. ${ }^{16}$

15 El marqués de Santa Cruz apresó unos 200 barcos enemigos a lo largo de su vida militar. A sus hazañas dedicaron dos poemas épicos Gaspar García de Alarcón (La victoriosa conquista que... hizo en las islas de los Açores el año de 1583, Valencia: Junto al molino de la Rouella, 1585) y Balthasar del Hierro (Libro y primera parte de los victoriosos hechos del muy valeroso cauallero don Aluaro de Baçán..., (Granada: René Rabut, 1561) reimpresos, el segundo en extracto, por Eduardo de Navascués (Coronas épicas en loor de D. Álvaro de Bazán, marqués de Santa Cruz, Madrid: Fortanet, 1888, 253 pp.). El mismo erudito publicó las Coronas heráldicas, líricas y épicas en loor de D. Álvaro de Bazán, marqués de Santa Cruz (ibid., 446 pp.); en él reproduce la carta de don Juan de Austria, fechada el 18 de octubre de 1572, en que da cuenta de los hechos a Felipe II (pp. 135-143, especialmente p. 141), y la Relación de los sucesos de la armada de la Santa Liga... de fray Miguel Servio (p. 133), quien aclara que como resultado de la operación quedaron libres 200 cristianos y se cautivaron 200 genízaros. La segunda parte del libro («Coronas líricas y épicas», pp. 343-432) reúne poemas dedicados al marqués por diversos ingenios; entre los menos conocidos están Benito Caldera, Lorenzo Flores, Mosquera de Figueroa, Ochoa de Lasalde, Pedro de Padilla, Pedro Rodríguez, Pedro de Torquemada, Vélez de Dueñas, Venegas y Quejada, y Cristóbal de Virués.

16 Ibid., f. 274. 
Virués recoge en v. 12 el epifonema del soneto acabado de citar, lo cual es índice de su desilusión, junto con el sintagma mil invencibles Rodomontes, que basta por sí solo para desacreditar un ejército.

Uno de los últimos poetas soldados de la época fue el conde Bernardino de Rebolledo (1597-1676), ingenio leonés que si a ratos mira hacia Góngora, muchos otros parece anticipar la sequía lírica del s. XVIII. Es lo que sucede con su Selva militar y política (1652), silva interminable compuesta de ocho divisiones y cuarenta distinciones en las que se repasan las guerras divinas y humanas desde la caída de Luzbel, sin acercarse a tiempos modernos más que para hacer análisis y dar consejos que nada perderían con estar en prosa. Sirva de muestra solo este fragmento:

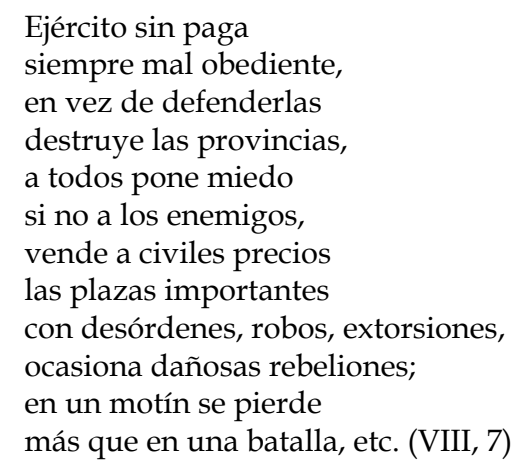

En los Ocios (1650), que recogen su obra lírica, la guerra aparece más en los epígrafes que en los textos, de los cuales solo destacaremos cuatro: las redondillas «Fabio, si has de ser soldado», en que trata de disuadir a un amigo de seguir la profesión militar; ${ }^{17}$ un romance en que «da cuenta a un amigo de los sucesos del ejército contra Holanda el año de 1640, en que era el autor teniente de maestre de campo general», y que tiene la originalidad de hacerlo en clave humorística; ${ }^{18}$ el soneto «a los estragos que la guerra hacía en Alemania, en las iglesias y en todo lo demás», ${ }^{19}$ y que, a pesar del epígrafe, es más bien un poema religioso, pues Rebolledo estuvo toda su vida obsesionado con defender la ortodoxia; y el soneto que «en el asedio de Copenhaven describe el estado de la plaza y el valor con que se defendía». Lo leeremos para que se pueda comparar con los del siglo anterior a similar asunto:

\section{El suelo d'enemigos ocupado, el mar al yelo siempre endurecido, el aire de contagios corrompido, el fuego de alimento despojado}

\footnotetext{
17 Ocios, ed. de Rafael González Cañal (Cuenca: Universidad de Castilla-La Mancha, 1997), p. 262.

18 Ibid., p. 404.

19 Ibid., p. 338.
} 
es el no poco riguroso estado a que nos ha la guerra reducido, repitiéndose el riesgo padecido y faltando el socorro deseado.

Victoriosos de asaltos tan sangrientos, el asedio nos es bien peligroso, temiendo más que a Ingalaterra y Francia

el favor que le dan los elementos, que nos prohíben aun lo más forzoso, pero todo lo vence la constancia. ${ }^{20}$

Después de apreciar el variable estro de los soldados, lo que ahora nos compete es ver cómo enfocan la guerra y sus parafernalia algunos de los más importantes poetas áureos sea cual sea su modo de vida. Poetas que, excusado es decirlo, sabían de la guerra menos que de cantar misa, y por ello no suelen mencionarla sino de forma abstracta o tangencial. No vamos a seguir un orden cronológico, sino de importancia por número de textos. En las Flores de poetas ilustres (1605), de Pedro Espinosa, solo se recogen tres poemas alusivos a la guerra: las canciones de Góngora, Agustín de Tejada y Mira de Amescua, que siguen visiblemente el modelo trazado por Herrera en las suyas sobre las batallas de Lepanto, las Alpujarras y Alcazarquivir. Las de Góngora y el Dr. Tejada (1567-1635) fueron escritas cuando aún no se sabía el fracaso de la Invencible, por lo cual corresponden más al género heroico que al bélico. Ambas denigran a la reina Isabel, lamentan la herejía de Inglaterra, profetizan la derrota del enemigo, en fin: hacen lo que pueden. ${ }^{21}$ Llama la atención que Lope de Vega no haya dedicado más que un soneto muy poco significativo a esa jornada, sobre todo si fuera cierto que participó en ella; ${ }^{22}$ pero no debemos olvidar que Lope se esforzó por ser poeta épico cantando legendarias hazañas medievales en la Jerusalén conquistada, y hechos recientes en $L a$ Dragontea, de forma que reservó la lírica para otros asuntos. Más cercano queda el asalto de Cádiz por los ingleses en 1596, al que Mira de Amescua (1570-1644) escribió la canción impresa en las Flores, asimismo irreal en sus planteamientos. ${ }^{23}$ El poeta, después de arremeter contra la reina Isabel, y de paso contra el género femenino, desafía «al indio, scita, egipcio, / macedonio, francés, inglés, fenicio», y termina exhortando a los delfines y sirenas para que arrojen a tierra los ingleses, y a Escila para que provoque

\footnotetext{
${ }^{20} \quad$ Ibid., p. 517.

21 Primera parte de las Flores de poetas ilustres de España, diuidida en dos libros. Ordenada por Pedro Espinosa, natural de la ciudad de Antequera (Valladolid: Luys Sánchez, 1605), ff. 5v y 11v.

22 Rimas, ed. crítica de Felipe Pedraza (Universidad de Castilla-La Mancha, 1993), I, p. 325. A juzgar por su primer terceto, el soneto parece puesto en boca de una mujer, como el famoso romance «De pechos sobre una torre».

23 Flores de poetas ilustres, f. 82v. El soneto de Lope de Vega «Atreviose el inglés, de engaño armado», incluido en La moza de cántaro, II, se duda si se refiere al primer ataque de Cádiz en 1596 o al segundo, de 1625, ya que la comedia habría sido compuesta en 1618 y revisada en 1625, según Morley-Bruerton.
} 
una borrasca que aniquile la escuadra enemiga. La conclusión, obvia, es que resultaba imposible componer obras maestras con solo buenos deseos.

No hace otra cosa que expresarlos la primera canción de Cervantes a la Invencible, «Bate, Fama veloz, las prestas alas», si es suya. Más segura parece la segunda, «Madre de los valientes de la guerra», que lamenta ya la derrota, atribuyéndola al mar y al viento. ${ }^{24}$ Es común que sobrevenga la fatiga en todos los géneros, en especial cuando usan de pie forzado, lo cual predispone para volverlos del revés. Tal sucede con el instrumento heroico, que puede convertirse en irrisorio a poco que las cosas se vean de cerca. Cervantes, soldado en su juventud, vivió lo suficiente como para presentarlas en su doble faz. El formidable soneto «a la entrada del duque de Medina en Cádiz», acaso por su maestría alguna vez atribuido a Góngora, es uno de los más desmitificadores del lamentable episodio cantado por Mira de Amescua:

Vimos en julio otra semana santa,

atestada de ciertas cofradías

que los soldados llaman compañías,

de quien el vulgo, no el inglés, se espanta.

Hubo de plumas muchedumbre tanta,

que, en menos de catorce o quince días,

volaron sus pigmeos y Golías

y cayó su edificio por la planta.

Bramó el becerro y púsolos en sarta, tronó la tierra, escureciose el cielo, amenazando una total ruina,

y al cabo, en Cádiz, con mesura harta, ido ya el conde, sin ningún recelo, triunfando entró el gran Duque de Medina. ${ }^{25}$

Según documentos fidedignos, al tener noticia del saco de Cádiz por el conde de Essex, el asistente de Sevilla encargó al capitán Becerra adiestrar un batallón de veinticuatro compañías de vecinos, que, después de ejercitarse varias semanas en Tablada, entraron en Cádiz con el duque de Medina Sidonia al frente, cuando el inglés, harto de saquear e incendiar la ciudad, ya se había marchado. La poco airosa actuación del duque vino así a cubrir de lodo su carrera militar, ya muy dañada desde el desastre de la Invencible. La frase vimos en julio que inicia el soneto, y el floreo verbal con el nombre del capitán en v. 9, suponen un testigo presente en Sevilla, como lo estaba Cervantes poco antes de sufrir prisión por deudas, o cualquier otro ingenio maleante y malicioso, como Álvarez de Soria.

\footnotetext{
${ }^{24}$ Cervantes, Comedias y Entremeses, tomo VI. Poesías sueltas, ed. de Rodolfo Schevill y Adolfo Bonilla (Madrid: Gráficas Reunidas, 1922), pp. 50 y 56 de la segunda numeración.

25 Ibid., p. 71 de la segunda numeración. A la fuente usada por Juan Antonio Pellicer pueden añadirse ahora los mss. 861, 3796 y 4117 BNM, dos más de la Hispanic Society, y otros de menor autoridad. Cf. Stanko S. Vranich, Ensayos sevillanos del Siglo de Oro (Valencia: Albatros, 1981), pp. 83-93.
} 
Gabriel Bocángel es bastante ajeno a los avatares de la milicia, aunque no deja de empuñar la lira para celebrar hechos insólitos: dedicó dos sonetos «A un soldado de quien se refiere que, matándole en un hecho de armas, se quedó un rato en pie después de muerto». ${ }^{26}$ Lo que los poemas dicen es fácil de suponer; ahora nos interesa resaltar que, si el hecho fue notable y los encomios tópicos, lo contrario sucede en el soneto cuyo epígrafe evoca una escena sencilla y ya de suyo sensiblemente poética: «Oyendo en el mar, al anochecer, un clarín que tocaba un forzado»:

Ya falta el sol, que quieto el mar y el cielo niegan unidos la distante arena: un ave de metal el aire estrena, que vuela en voz cuanto se niega en vuelo.

Hijo infeliz del africano suelo es, que, hurtado al rigor de la cadena, hoy música traición hace a su pena, si pena puede haber donde hay consuelo.

Situación, pues, inversa de la cantada en el romance de Góngora «Amarrado al duro banco», y que Bocángel deriva en los tercetos hacia sus cuitas amorosas; pero la compasión que le inspira un africano forzado a remar en galeras cristianas sorprende por su novedad. ${ }^{27}$ Mucha menos presenta la única composición de asunto bélico de un autor también tardío, Trillo y Figueroa, el romance «pintando la batalla que el duque de Alburquerque tuuo con el marqués de la Fara, junto a Villafranca de Panadés en Cataluña». Se trata una vez más del género epidíctico, adornado con copia de mitología y exagerando la inferior condición en que peleaba el español respecto al francés, que resultó muerto en la contienda. ${ }^{28}$ Tampoco nos va a entretener la canción lúgubre «Al húngaro Tiburcio, en la opresión de Esmirna», de Jáuregui, que, a pesar de su epígrafe, no pasa de ser un ataque más al lenguaje culto. ${ }^{29}$

El príncipe de Esquilache (1577-1658) es un poeta cuyo prestigio en vida contrasta con el olvido que hoy sufre. Tras ejercer de virrey en Perú (1614-1621), vegetó largos años en dorada oscuridad, casi siempre en la corte, sin darse prisa por publicar. En la segunda edición de sus Obras en verso ${ }^{30}$ hay tres sonetos y tres canciones que aluden a

\footnotetext{
26 Bocángel, Obras completas, ed. de Trevor J. Dadson (Madrid: Universidad de Navarra-Vervuert, 2000), I, pp. 131-132. Otro similar inspira a Ulloa el soneto «No yace, resplandece en la muralla», compuesto «A la muerte de vn caballero que, asaltando una muralla, se abraçó con un francés que la defendía, y se mataron los dos a puñaladas» (Versos, Madrid: Diego Díaz, 1659, f. 29v).

27 Ibid., p. 434. Lo mismo hará Francisco Manuel de Melo al rematar su soneto escrito «En el mal sucesso de vna batalla» (Obras Métricas, León de Francia: Horacio Boessat y George Remeus, 1665, El Harpa de Melpómene, p. 63).

28 Francisco de Trillo y Figueroa, Obras, ed. de Antonio Gallego Morell (Madrid: CSIC, 1951), p. 623.

29 Poesía, ed. de Juan Matas Caballero (Madrid: Cátedra, 1993), p. 319.

30 Amberes: Imprenta Plantiniana de Balthasar Moreto, 1654.
} 
la guerra con Francia en el País Vasco y Cataluña. Una guerra, esta última, historiada por el poeta hispano-portugués Francisco Manuel de Melo, testigo de alguno de sus episodios, y que sin embargo no dejó la menor huella en su obra poética ni castellana ni portuguesa. En cuanto a Esquilache, que la contempló de lejos, tampoco lo desvaído de sus poemas bélicos parece reflejar más que un cumplido forzoso en quien era asiduo de palacio y poeta favorito de Felipe IV. El asedio de Fuenterrabía por el príncipe Condé fue muy sonado en España, no solo por haber durado más de dos meses, sino porque en defender la plaza puso todo su empeño el conde-duque de Olivares, hasta el punto de ser considerado artífice de la victoria, aun cuando otros, cuyo corifeo literario es Calderón, atribuían la hazaña al Almirante de Castilla. ${ }^{31}$ Nada de ello se trasluce en el soneto «Dexó dos casas el mayor planeta», en que Esquilache glosa el suceso en lenguaje bastante críptico. ${ }^{32}$ Poco más brío despliegan los poemas que celebran el socorro de Lérida: el soneto «Siete vezes mudó jornada y casa», cuyo mérito radica en la sentencia, es decir, en su verso final, que habla de como las lises pudieron «solo durar lo que en morir tardaron», ${ }^{33}$ y otro soneto al mismo asunto que no fue recogido en las Obras, aunque parece auténtico:

Ya el imbencible monte leridano, al yugo del primer César esempto, yace a tu planta: ¡illustre rendimiento, o valiente campeón, César cristiano!

Del catalán al persa, al africano, pase tu campo vitoriosso, attento de tu bridón al fuerte movimiento, de tu bastón al orden soberano.

Triunpha veloz de quanto imperio vaña el sol, que en tu corona se ha escogido, por más illustre cassa de su esphera,

para medir contigo la campaña; y quanta fiera no murió al bramido, león invicto, a tu presencia muera. ${ }^{34}$

Tanto este soneto como la silva «Los que la dulce voz de mi Talía», lejos de entrar en detalles, animan al monarca a nuevas campañas contra el portugués, el turco,

31 Cf. la relación del obispo Palafox, Sitio y socorro de Fuenterrabía... (Madrid: Catalina del Barrio, 1639), E. M. Wilson, «Calderón y Fuenterrabía: el Panegírico al Almirante de Castilla», BRAE, XLIX (1969), pp. 253-278, y el bien documentado libro de Antonio Bernal de O’Reilly, Bizarría guipuzcoana y sitio de Fuenterrabía, 1474-1521, 1635-1638 (San Sebastián: Juan Osés, 1872). Estudia las repercusiones de estos episodios $\mathrm{M}^{\mathrm{a}}$ Soledad Arredondo, «La corte celebra las victorias de la guerra: Fuenterrabía y Lérida», José $\mathrm{M}^{\mathrm{a}}$ Díez Borque, Esther Borrego y Catalina Buezo (eds.), Literatura, política y fiesta en el Madrid de los siglos de oro (Madrid: Visor, 2009), pp. 17-41.

32 Obras en verso, p. 43.

33 Ibid., p. 14.

34 Ms. 2376 BNM, f. 157. Publicado por Justo Gómez Ocerin, «Del príncipe de Esquilache», RFE, V (1918), p. 299. Cf. también la Relación [...] sobre el sitio y socorro de Lérida, de Gracián, Madrid: Carlos Sánchez, 1646. 
el persa y el africano. ${ }^{35}$ Hasta qué punto el poeta creía en sus exhortaciones y vaticinios es imposible saberlo, pero muy ingenuo sería si, viendo a España rota por varios sitios y todas las cosas en estado precario, pensara que el país podía arrojarse a empresas tan rentables y hacederas como la conquista de los santos lugares. Más comedida se muestra la canción XXII «en la recuperación de Barcelona y Principado de Cataluña», centrada en la clemencia real, como también el soneto «Adonde Llobregat humilde aspira». ${ }^{36}$ Dicho con poca diplomacia, Esquilache al escribir sobre los conflictos guerreros en que España se vio envuelta a mediados del siglo no intenta más que ganar puntos de vate áulico.

Tampoco entra mucho en materia Quevedo, a pesar de su facundia. Así como Esquilache fustiga las guerras civiles en el soneto «Con fuerza igual, con águilas parciales», ${ }^{37}$ que evoca la de César y Pompeyo, también Quevedo se remonta a Troya, Cartago y Sagunto, en el salmo XII de su Heráclito Cristiano, para extraer de su ejemplo desengaños. ${ }^{38}$ Más próxima parece la moraleja del soneto que «descubre quién lleva los premios de las victorias marciales», donde, usando de la paradoja y del cinismo, aconseja al destinatario con estas palabras: «Druso, acomoda con la edad la mente, / guarda para la paz lo belicoso, / aprende a ser en el peligro ausente» ( $\left.n^{\circ} 108\right)$. Tal actitud antiheroica contrasta con los elogios a Scévola ( $\left.n^{\circ} 218\right)$, el duque de Osuna (núms. 215, 242, 243), Wallenstein ( $\mathrm{n}^{\mathrm{o}} 263$ ) o don Fadrique de Toledo $\left(\mathrm{n}^{\mathrm{o}} 264\right)$, aunque por otras vías sepamos que en la guerra no todo para Quevedo consistía en valor y caballerosidad. De los tres sonetos dedicados al duque de Osuna, el que comienza «Vulcano las forjó, tocolas Midas» ( $\mathrm{n}^{\circ}$ 215), es en realidad un ejercicio de ékphrasis, sobre el retrato del duque pintado por Guido Boloñés. En cambio, los otros dos muestran al mejor Quevedo, lleno de dolor en el primero ( $\mathrm{n}^{\mathrm{o}} 242$ ), no tanto por la pérdida de su amigo, cuanto por el tipo de muerte que sufrió, más propia de un delincuente: el verso «Divorcio fue del mar y de Venecia» sintetiza en pocas palabras la acción del gran duque, capaz él solo de atemorizar a la República esposa y dueña del Adriático; pero aún le gana la inesperada exclamación: «¡Y a tanto vencedor venció un proceso!», que abre el primer terceto, solo para descender en los siguientes versos. Asimismo noble es el segundo soneto $\left(\mathrm{n}^{\circ} 243\right)$, titulado «Compendio de las hazañas del mismo en inscripción sepulcral», que arranca con esta enumeración:

\footnotetext{
35 Las Obras en verso, cit., pp. 256-259. Sobre otros aspectos de este poeta, cf. A. Carreira, «El modo menor en la lírica del príncipe de Esquilache», Monique Güell y Marie-Françoise Déodat-Kessedjan (eds.), Le plaisir des formes dans la littérature espagnole du Moyen Âge et du Siècle d'Or (Toulouse: Université de Toulouse-Le Mirail, 2008), pp. 123-138.

36 Las Obras en verso, cit., pp. 308-311 y 17.

37 Las Obras en verso, cit., p. 18.

38 Obra poética, ed. de J. M. Blecua (Madrid: Castalia, 1969), nº 24.
} 
Diez galeras tomó, treinta bajeles, ochenta bergantines, dos mahonas; aprisionole al Turco dos coronas y los cosarios suyos más crueles.

Sacó del remo más de dos mil fieles, y turcos puso al remo mil personas...

Bastaría recordar el soneto antes citado de Virués sobre Navarino para confirmarnos en su sentido irónico, mientras que el de Quevedo, implacable con los enemigos, casi amontona hazañas antes de proseguir, en curiosa visión retrospectiva, con la hoja de servicios del duque, tan mal agradecida por los políticos de turno.

Quevedo, ya se sabe, cuando es rebelde, lo es en el lenguaje, no en la ideología. Otros poemas suyos a asuntos heroicos manifiestan su conformismo a la vez que su incontinencia verbal. Así sucede con el soneto-exhortación a Felipe IV donde llama al Belga «habitador violento / de poca tierra, al mar y a ti robada», y hace votos por que el rey, cual nuevo Júpiter, fulmine al Belga, al Francés, al Sueco y al Germano ( $\left.n^{\circ} 219\right)$. Tópica y verbosa es la silva en que celebra la captura de varios bajeles redondos de turcos por el duque de Pastrana; aquí la adulación enseña demasiado la oreja, sin que entre 72 versos puedan destacarse más que estos: «Sonora resbalaba vuestra quilla / haciéndose menor siempre la orilla» $\left(\mathrm{n}^{\mathrm{o}} 236\right) \cdot{ }^{39}$ No vemos razón para no tomar en serio las ideas expresadas por Quevedo en su célebre «Epístola satírica y censoria contra las costumbres presentes» ( $\left.\mathrm{n}^{\mathrm{o}} 146\right)$, puesto que la dirige, en tono solemne, al conde-duque de Olivares, entonces ministro todopoderoso. Una lectura atenta permite desvelar que don Francisco viste con sus mejores galas ideas propias del arbitrista más desquiciado: vuelve sus ojos a una época heroica en que «Hilaba la mujer para su esposo / la mortaja, primero que el vestido» y «acompañaba el lado del marido / más veces en la hueste que en la cama». Cuál fuera aquel periodo feliz en que «sólo se cudiciaba lo decente», en que «bebió la sed los arroyuelos puros» $\mathrm{y}$ «tan bien como el señor comió el esclavo», no lo sabemos: Quevedo parece creer no solo en su realidad histórica sino en la conveniencia de regresar a él, a fin de fortalecer a España curándola de flaquezas y contagios morunos. Todo ese delirio culmina en la silva-execración «al inventor de la pieza de artillería» ( $\left.\mathrm{n}^{\circ} 144\right)$, que a Quevedo, no menos que a don Quijote, le parece algo salido del averno. ${ }^{40} \mathrm{He}$ aquí algunas de sus razones:

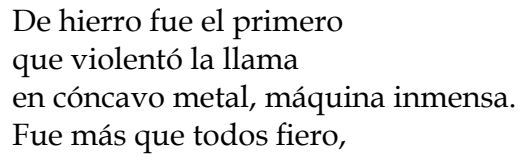

\footnotetext{
$39 \mathrm{Al}$ hecho dedicó López de Zárate el soneto «Sangre del que en borrascas de agua y fuego» (Obras varias, ed. de José Simón Díaz, Madrid: CSIC, 1947, II, p. 31).

40 Como se lo parece a Ariosto, de donde procede el motivo. Cf. Orlando furioso, IX, 89-91 y XI, 26-28.
} 


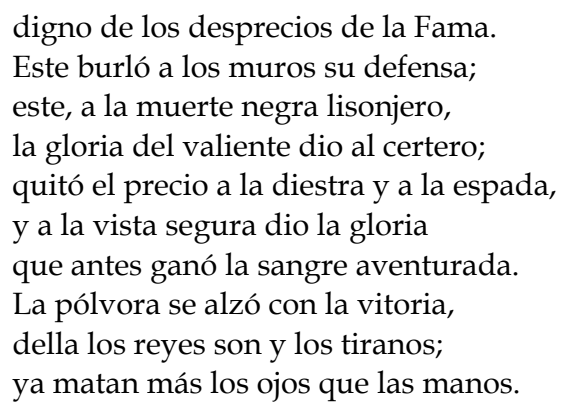

Claro es que las hazañas del duque de Osuna, por ejemplo, habían tenido como base la artillería, pero el espadachín Quevedo no se acuerda de eso, sino que se deja llevar de su peculiar caballería andante, como si la evolución del mundo y la poliorcética hubieran debido detenerse, por razones ignotas, en la edad media. De igual manera podría haber injuriado al inventor de la ballesta, que tanta revolución supuso hacia el siglo XII y fue mal vista por la iglesia, o al del asedio por hambre, donde tampoco son las manos quienes matan. Mucho más sensato parece Quevedo cuando en el Buscón (II, 1) se burla de aquel arbitrista que pretendía resolver la toma de Ostende chupando el mar con grandes esponjas. Denostar la guerra puede pasar como ejercicio retórico, pero querer imponerle normas desde un poema no deja de ser una ingenuidad.

Más de veinte poemas o fragmentos de Góngora tocan la guerra, casi nunca en serio. Hemos mencionado el que dedicó a la Invencible, hecho también aludido desde una perspectiva nada reverencial en el romance "Ahora que estoy de espacio», donde después de pintar su vida en la aldea, cazando, cantando en el coro o jugando con el alcalde y el cura, añade: «Gobernaba de allí el mundo / dándole a soplos ayuda / a las católicas velas / que el mar de Bretaña surcan». ${ }^{41}$ Estos versos expresan con nitidez cómo Góngora, rebelde a ratos y siempre vividor, contempla hechos que no le conciernen: ni aprueba ni condena, simplemente los mira de lejos, y con mucha sorna. Ocho años después, a raíz de otra intentona antibritánica, insiste en la cuchufleta:

$$
\begin{aligned}
& \text { A las armas, mozalbitos, } \\
& \text { que un navío filipote } \\
& \text { os espera en El Ferrol: } \\
& \text { plega a Dios que se derrote. } \\
& \quad \text { Haced en Ingalaterra } \\
& \text { nobilísimo cerote, } \\
& \text { reduciendo al calvinista, } \\
& \text { saqueando al hugonote. }{ }^{42}
\end{aligned}
$$

\footnotetext{
${ }^{41}$ Góngora, Obras completas, I, ed. de A. Carreira (Madrid: Fundación José Antonio de Castro, 2000), p. 100.

${ }^{42}$ Ibid., p. 171.
} 
Esta dualidad está asimismo presente en los poemas consagrados a la toma de Larache, una canción y un soneto compuestos en el modo sublime, frente a otro soneto y dos poemas en décimas que ponen en solfa toda la empresa. De ellos es inevitable transcribir el soneto, fechado en 1608 y referido a uno de los intentos fallidos de conquistar Larache, porque se trata de uno de los más cáusticos de nuestra literatura antimilitarista:

- ¿De dónde bueno, Juan, con pedorreras?

- Señora tía, de Cagalarache.

- Sobrino, ¿y cuántos fuistes a Alfarache?

- Treinta soldados en tres mil galeras.

- ¿Tanta gente? - Tomámoslo de veras.

- ¿Desembarcastes, Juan? - Tarde piache,

que al dar un Santïago de azabache,

dio la playa más moros que veneras.

- ¿Luego es de moros? -Sí, señora tía:

mucha algazara, pero poca ropa.

- ¿Hicieron os los perros algún daño?

- No, que en ladrando con su artillería, a todos nos dio cámaras de popa.

-Salud serían para todo el año. ${ }^{43}$

El diálogo lleno de equívocos entre el soldado cobardón y la tía medio sorda es tan demoledor, que sorprende cómo el poema no fue objeto de censura en la edición de 1627; acaso lo salvó el tratar de una empresa poco gloriosa del equipo gobernante regido por el duque de Lerma y caído en desgracia diez años antes.

Hay no obstante unos romances de Góngora en que se combina el tono sentimental con el heroico: los que inauguran la serie de cautivos («Amarrado al duro banco», «La desgracia del forzado») y dos más de la serie morisca («Entre los sueltos caballos», «Servía en Orán al rey»), modalidad esta que, a diferencia de la anterior, pronto será vuelta del revés; el mismo tono emplea el célebre y temprano romancillo «La más bella niña», cuya protagonista lamenta la marcha de su amado a una guerra que podría ser la de las Alpujarras o la de anexión de Portugal. A ellos pueden añadirse un par de sonetos dedicados al marqués de Santa Cruz y a la Austriada de Juan Rufo, y la temprana canción compuesta en elogio de la versión española de Os Lusiadas. Pero los dos últimos poemas son metaliteratura, y varios de los anteriores, más que ante la guerra en sí nos ponen ante sus consecuencias. Los restantes que se asoman directamente al tema bélico lo hacen en son de bufa. Veinte años tenía el poeta cuando escribió estos versos:

Que el mochilero o soldado

deje su tercio embarcado,

33 Ibid., p. 263. 
bien puede ser;

mas que lo crean de la guerra

porque entró roto en su tierra,

no puede ser. ${ }^{44}$

He aquí un tema recurrente en Góngora, el del miles gloriosus. A él dedicará todo el romance «Pensó rendir la mozuela», asimismo juvenil, parte del cual, puesto en boca del alférez de mentira, enumera en forma cínica sus dudosos méritos. ${ }^{45}$ Por esas fechas vuelve a la carga en varias letrillas:
Al que de sedas armado, tal para Cádiz camina que ninguno determina si es bandera o si es soldado, de su voluntad forzado, llorado de sus amigas, siete higas. ${ }^{46}$

Este motivo de los adornos, plumas o telas de colores, con que se ataviaban los soldados, lo hemos visto en Cervantes y reaparecerá en los sonetos de Góngora a la Mamora. De nuevo en la letrilla «A toda ley, madre mía», una moza retoma la vieja disputa sobre el clérigo y el caballero, dejando a este muy mal parado:
Orlandos enamorados, que después dan en furiosos, en las paces belicosos, en las guerras envainados, de bigotes engomados y de astróloga contera, nunca Dios me haga nuera de la hermana de su tía. ${ }^{47}$

Claro es que la guerra en este caso se reduce al aparatoso aspecto de un matón. Pero una letrilla de 1600 vuelve a reírse del soldado que cifra su valor en el relumbre de las galas:
Con dos puñados de sol y cuatro tumbos de dado repite el otro soldado para conde de Tirol; fénix lo hacen español collar de oro y plumas bellas; despidiendo está centellas

\footnotetext{
$\overline{44}$ Ibid., p. 13 (letrilla «Que pida a un galán Minguilla»).

45 Ibid., p. 106.

46 Ibid., p. 146 (letrilla «Un buhonero ha empleado»).

47 Ibid., p. 149.
} 
de sus joyas, mas la suerte

en gusano lo convierte,

de pájaro tan galán.

Los dineros del sacristán

cantando se vienen y cantando se van..$^{48}$

Tanta insistencia parece indicar que la ficción bélica, como la del peregrinaje u otras, era una variante más de la picaresca, algo que podía afectar por igual a los caballeros, a juzgar por el soneto «Sea bien matizada la librea». Mucho antes de escribirlo se había reído Góngora de la tela de justar puesta junto al Manzanares, porque, según sabemos y acredita el soneto «Tengoos, señora Tela, gran mancilla», la gente iba a verla, pero los caballeros no la habían estrenado. El colmo de la irrisión se encuentra en los dos sonetos compuestos en 1614 «a la bajada de muchos señores de la corte al socorro de la Mamora, que estaba cercada», según reza el epígrafe del primero:

- ¡A la Mamora, militares cruces!

¡Galanes de la corte, a la Mamora!

Sed capitanes en latín ahora

los que en romance ha tanto que sois duces.

- ¡Arma, arma, ensilla, carga! — ¿Qué, arcabuces?

-No, gofo, sino aquesa cantimplora;

las plumas riza, las espuelas dora.

- ¿Ármase España ya contra avestruces?

- Pica, bufón. ¡Oh tú, mi dulce dueño!

Partiendo me quedé, y quedando paso

a acumularte en África despojos.

- ¡Oh tú, cualquier que la agua pisas leño!:

escuche la vitoria yo, o el fracaso,

a la lengua del agua de mis ojos. ${ }^{49}$

Aunque el soneto carece de didascalias, en él suenan cuatro voces bien diferenciadas: una primera que sería la voz oficial, por decirlo así, encargada de animar a los nobles a cumplir con su deber; la segunda y la tercera, de un caballero y su criado que dialogan en el segundo cuarteto y primer terceto; y la cuarta, en el segundo terceto, que parece corresponder a la amada del caballero. Aunque en los vv. 3-4 la exhortación reza: «Sed capitanes en latín ahora / los que en romance ha tanto que sois duces», tal vez haya que aceptar la variante de Pellicer: «Sed capitanes en romance... / los que en latín... sois duces» (Lecciones solemnes, 746-747), puesto que, en efecto, se invita a quienes son duques o cosa equivalente a recuperar el sentido militar originario de su rango; no basta con exhibir el título más o menos pomposo sino que es preciso ejercitarlo. Pero lo que sigue hace perder toda esperanza: al prócer no le importan los arcabuces sino los plumajes, el dorado de las espuelas y la cantimplora. Cantimplora

\footnotetext{
48 Ibid., p. 190 (letrilla «Los dineros del sacristán»).

49 Ibid., p. 425.
} 
cuyo «fresco rumor», junto con las plumas, aparece también en el segundo soneto al mismo asunto, y que es en realidad una epístola, o, mejor, un billete con lugar, fecha y firma:

Llegué, señora tía, a la Mamora, donde entre nieblas vi la otra mañana, desde el seguro de una partesana, confusa multitud de gente mora.

Pluma acudiendo va, tremoladora, andaluza, extremeña y castellana, pidiendo, si vitela no mongana, cualque fresco rumor de cantimplora.

Allanó alguno la enemiga tierra echándose a dormir; otro soldado, gastador vigilante, con su pico

biscocho labra. Al fin, en esta guerra no vi más fuerte sino el levantado. De la Mamora, hoy miércoles, Juanico. ${ }^{50}$

La constante ironía y las bisemias transparentes hacen de este soneto el complemento perfecto del anterior, más cómico por su disposición entremesada, y ambos forman un díptico insuperable de humor y maledicencia. Góngora en 1614 no debe nada a nadie, vive en Córdoba, está incluso liberado de la obligación de asistir al coro catedral, su tiempo y sus rentas le pertenecen, y así, desde el seguro de esa parte sana, por decirlo con sus palabras, se permite juzgar con libertad los heroísmos ajenos. Es fácil de imaginar la chirigota que se armaría en los corrillos de sus amigos cuando el poeta, famoso por su lengua viperina, diese a conocer estos sonetos.

Son bastantes los textos gongorinos que revelan escepticismo por parte de su autor. No podemos apreciar si es característica suya más que de otros, pues el grado de sinceridad de los poetas es siempre un misterio, pero cabe postular, contra la opinión habitual, que todos viven una época de descreimiento, de valores en declive. En los poemas mencionados habla alguien que, desde muy joven, supo distinguir al héroe del pícaro, lo auténtico de lo inauténtico, e hizo poesía de alta calidad solo con dejar claro que las cosas no suelen ser lo que parecen. Las «Coplas de Coridón», poema en cinco décimas compuesto en 1612, es el clímax de esa postura clarividente; alguna vez lo hemos relacionado con El Criticón de Gracián, casi medio siglo posterior, ya que en ambas obras dialogan dos personajes, uno que juzga por las apariencias, y otro que lo saca de su engaño. Góngora exalta empresas militares en el epilio de la primera Soledad, donde canta con embeleso los descubrimientos y las conquistas de españoles y portugueses. Pero esos hechos pertenecen al pasado, el filtro de los años les ha suprimido toda excrecencia de mezquindad humana. Es como si dijera que la

$50 \quad$ Ibid., p. 426. 


\section{Antonio Carreira}

epopeya y la tragedia no pueden darse en nuestra edad de hierro, o que nuestros ojos carecen de suficiente inocencia para apreciarlas en la realidad. 